\title{
Solitary Rectal Ulcer Syndrome: Uncommon Cause of Rectal Bleeding in Children
}

\author{
KC S, ' Sharma S,' Basnet B, 'Mishra AK' \\ Liver Unit, National Academy of Medical Sciences, Kathmandu, Nepal
}

\section{ABSTRACT}

Rectal polyp and hemorrhoids are common causes of bleeding per rectum in pediatric age group. However, there are some other causes which should be considered in differential diagnosis. We have acquainted a case of rectal bleeding due to solitary rectal ulcer in a child of 10 year. Colonoscopic examination was required for diagnosis as proctoscopic examination and digital rectal examination missed the diagnosis, probably due to poor co-operation by the patient and rare nature of the disease. Although well recognized in the adult population, the pediatric experience with this condition is limited.

Key word: children, rectal bleeding, solitary rectal ulcer

\section{INTRODUCTION}

Solitary rectal ulcer syndrome (SRUS) was first reported in 1830 and established in 1968, it is a benign condition of the rectum that affects predominantly young adult females aged between 30 and 50 years with a prevalence of 1 in 100000 people per year. ${ }^{1,2,3}$ Unless recognised, the diagnosis can be delayed and be mistaken for non-specific ulcer, inflammatory bowel disease or neoplasm

In children it often remains unrecognised. A greater awareness of the condition will lead to more frequent diagnosis. In a series of 256 children with rectal bleeding from Iran, Dehghani et al diagnosed SRUS in 12 (5\%) on colonoscopy and histology examinations. It should be suspected in children with a history of constipation, straining at stool, mucoid stool with or without perianal pain presenting with rectal bleeding.

\section{CASE REPORT}

A 10-year-old girl with normal developmental milestone was brought to the Emergency room with complaint of fresh bleeding, three episodes amounting around 150 $\mathrm{ml}$, from anus after straining for stool. She gave history of constipation and straining on stool for more than six years that was often relieved by giving enema. There

\author{
Correspondence: \\ Dr. Sudhamshu KC \\ Liver Unit, National Academy of Medical Sciences \\ GPO Box no. 2983, Kathmandu, Nepal \\ Phone:+977-9851081599 \\ E-mail: Sudhamshu.liver@gmail.com
}


KC et al. Solitary rectal ulcer in children

was history of mucoid stool at several occasions in last three years. There was no history, recent or past, of digital manual evacuation by the patient or her family members. There was no family history of hemorrhoids or intestinal cancer. At the time of examination, there was no sign of shock or dehydration. Blood examination showed normal hemoglobin and hematocrit value. Digital rectal examination and proctoscopic examination was negative for hemorrhoids. Finger was blood stained and hard stool was palpable. She was given stool softner and discharged with advice to attend OPD for further investigations including colonoscopic examination. She didn't come for the invstigations probably due to no symptoms. But she re-bled and attended emergency again after 3 days. She was admitted for further investigation. Her vitals were normal at the time of admission. Hemoglobin and hematocrit was again within normal limits. Coagulation profile was normal. She underwent colonoscopic examination under intravenous propofol and revealed a solitary white base rectal ulcer, $3 \times 3.5 \mathrm{~cm}$ size at a distance of $5 \mathrm{~cm}$ from anal verge. There was little amount of fresh blood in the margin (figure 1,2 ). There were no stigmata of recurrent bleeding. No bleeding vessels or blood clots were seen. Histopathology revealed normal crypt pattern and adequate goblet cell population. A couple of epithelium showed underlying muscularis with focal inflammatory granulation tissue. There was abundant fibropurulent exudate on the surface (Figure 3 and 4). Based on history, clinical examination, colonoscopic examination and histopatholgical findings a diagnosis of solitary rectal ulcer syndrome was made. She was kept for observation for 24 hours. Post procedure period was un-eventful. On discharge she was prescribed intestinal pro-kinetic agent, stool softner and dietary modification. The patient improved with conventional treatment. There is no re-bleeding after three months of diagnosis. Repeat colonoscopic examination was advised but it was denied by the patient party.

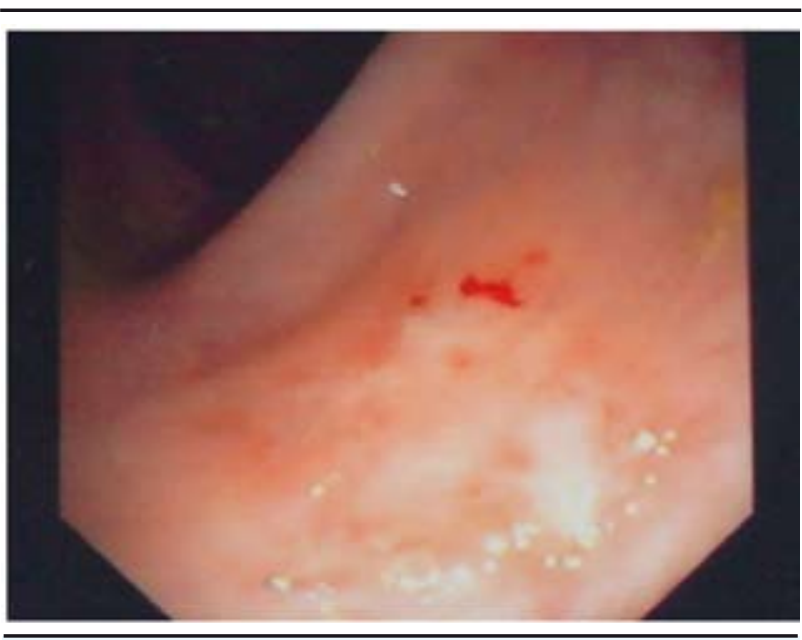

Figure 1. Rectal ulcer with fresh blood in the margin.

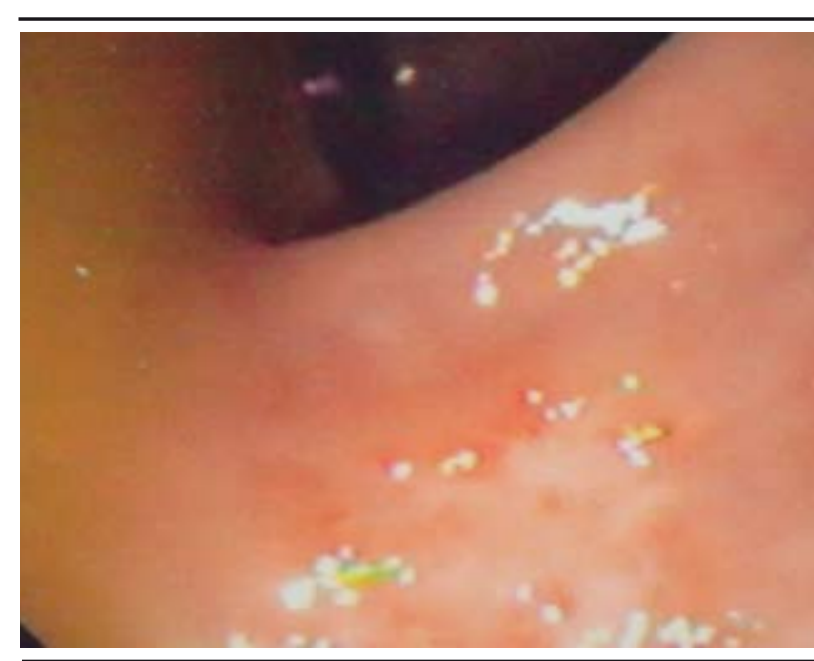

Figure 2. Ulcer after washing with water. Biopsy was taken from the site shown by arrow.

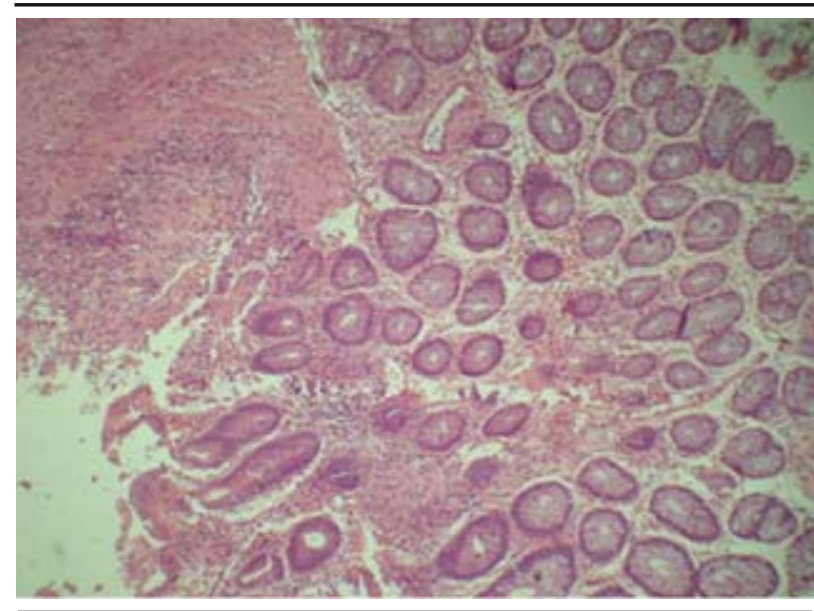

Figure 3. Section of the lesion showing inflamed colonic mucosa and adjacent ulcer base consisting of inflammatory granulation tissue and underlying muscularis.

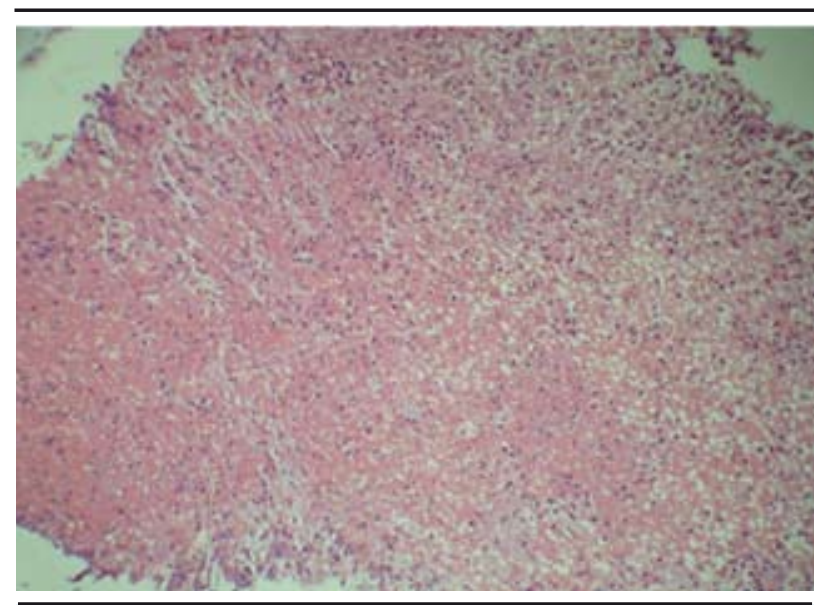

Figure 4. Section showing fibrinoid material with plenty of neutrophils which is compatible with ulcer surface. 
KC et al. Solitary rectal ulcer in children

\section{DISCUSSION}

Solitary rectal ulcer syndrome can present with bleeding, passage of mucus, straining during defecation and a sense of incomplete evacuation. In a study carried out in Indonesia, common presenting symptoms were rectal bleeding $(86 \%)$, abdominal pain $(36 \%)$, mucus per rectum $(25 \%)$, straining at defaecation (25\%), diarrhoea $(14 \%)$ and constipation (14\%). ${ }^{4}$ The pathogenesis of the syndrome is still not clear. It is postulated that the excessive straining efforts during defecation causes high intraabdominal pressure and forces the anterior rectal mucosa firmly into the contracting puborectalis muscle. The anterior rectal mucosa is frequently forced into the anal canal and as a consequence becomes strangulated, causing congestion, edema, and finally there is ulceration. ${ }^{5}$ The most common clinicopathologic diagnostic confusion may be inflammatory bowel disease, infectious proctocolitis, intussusception, hemorrhoids, prolapsing rectal polyp, or sexual abuse.

On colonoscopy a single ulcer is found in $70 \%$ of cases that is usually located anterior or lateral side of valves of Houston..$^{2,7}$ The appearance of ulcer on colonoscopy may vary from preulcer hyperemic changes of rectal mucosa to established ulcers. It has been noted previously that the term "solitary rectal ulcer" is a misnomer because only one fourth of the adults with SRU have true rectal ulcer, and the lesion is not necessarily solitary or ulcerated. ${ }^{6}$ In $25-30 \%$ cases the ulcer may be polypoid or multiple. ${ }^{2,3}$
The treatment of SRUS in children is guided by symptoms, findings on physical examination and investigations. The initial clinical approach of SRUS in children should be reassurance of the child and the parents about the benign nature of the disease and to suggest conservative measures, which include avoidance of straining, use of high-fiber diet, and intermittent use of laxatives to prevent constipation. Our case was also managed conservatively and till last follow up there was no recurrence. In some cases, SRUS can be difficult to treat and the ulcer may recur. In the absence of overt rectal prolapse, however, a conservative treatment includes intake of high fiber diets, plenty of fluids, stool softener, laxatives and bowel retraining to avoid straining on defecation. This case was managed by conservative treatment. However, it is too early to say that the treatment is complete as repeat colonoscopy is yet to be done. Follow up for few more months is needed. In difficult cases different treatments have been used with various responses and improvement of symptoms using enemas containing sucralfate, salicylate, corticosteroid, sulfasalazine, mesalazine and topical fibrin sealant. ${ }^{8}$ Malignant transformation of the ulcer is not yet reported.

\section{CONCLUSIONS}

Solitary rectal ulcer can cause rectal bleeding in children. It should be considered as differential diagnosis in any age group. Meticulous proctoscopic examination may avert requirement of colonoscopic examination, especially in pediatric population when anesthasia is required.

\section{REFERENCES}

1. Cruveilhier J. Chronic ulcer of the rectum. Pathological anatomy of the human body [in French]. Paris: JB Bailliere; 1830 .

2. Madigan MR, Morson BC. Solitary ulcer of the rectum. Gut 1969; 10:871-81.

3. Martin CJ, Parks TG, Biggart JD. Solitary rectal ulcer syndrome in NorthernbIreland 1971-1980. Br J Surg 1981; 68:744-747.

4. Chong VH, Jalihal A. Solitary rectal ulcer syndrome: characteristics, outcomes and predictive profiles for persistent bleeding per rectum. Singapore Med J. 2006 Dec;47(12):10638.

5. Ford MJ, Anderson JR, Gilmour HM, et al. Clinical spectrum of “solitary ulcer" of the rectum. Gastroenterology.1983;84:15331540

6. Ertem D, Acar Y, Karaa EK, Pehlivanoglu E. A rare and often unrecognized cause of hematochezia and tenesmus in childhood: solitary rectal ulcer syndrome. Pediatrics. 2002 Dec;110(6):e79.

7. Choi HJ, Shin EJ, Hwang YH, Weiss EG, Nogueras JJ, Wexner SD. Clinical presentation and surgical outcome in patients with solitary rectal ulcer syndrome. Surg Innov 2005; 12:307313.

8. Keshtgar AS. Solitary rectal ulcer syndrome in children. Eur J Gastroenterol Hepatol 2008 Feb;20(2):89-92. 